\title{
POTRET PENGUBURAN JANAZAH DALAM ISLAM MERUPAKAN BENTUK KEPEDULIAN SOSIAL DUNIA-AKHIRAT
}

\author{
Imam Baihaki \\ imambaihakiilyas@gmail.com \\ STAI Nurul Huda Kapongan Situbondo
}

\begin{abstract}
Abstrak
Sikap saling tolong menolong, dan saling peduli menjadi salah satu cirri khas dalam budaya Islam, kepedulian sosial dalam Islam bukan sekedar slogan, melainkan menjadi dasar keimanan. Berkaitan dengan hubungan sosial Allah mengingat hubungan ini dengan perintah merealisasi ukhuwah, kecintaan, kasih sayang, saling menghormati, tolong menolong, saling mempersatukan, solidaritas, bahkan sampai kepada tingkat itsar (mendahulukan orang lain) dalam masalah kehidupan. Dalam hal ini dalam Al-qur`an memerintahkan untuk tolong menolong dalam aksi kepedulian sosial, lebih lebh jika keluarga kita membutuhkan pertolongan untuk dibantu. Terlebih jika sanak saudara kita meninggal, mereka membutuhkan pertolongan kita yang sangat tinggi. Hasil dari penelitian ini menunjukkan bahwa dalam potret penguburan jenazah dari berbagai tempat banyak yang menimbulkan persoalan, tradisi penguburan jenazah sering kali menjadi pembicaraan dikalangan masyarakat. Sehingga penelitian pustaka ini sedikit memberi ulasan tentang bagaimana tradisi penguburan jenazah dalam Islam yang merujuk kepada Al Quran dan Hadist.
\end{abstract}

Keyword : Tradisi, Janazah, Qur`an, Hadist

\section{PENDAHULUAN}

Kajian tentang budaya tolong-menolong telah banyak di teliti di berbagai daerah. Pada masyarakat jawa Kebudayaan tolong-menolong atau gotong-royong inidikenal dengan kebudayaan Sambatan. ${ }^{1}$ Sambatan merupakan suatu sistem gotongroyong dengan cara menggerakkan tenaga kerja secara masal yang berasal dari warga kampung itu sendiri untuk membantu keluarga yang sedang tertimpa musibah atau sedang mengerjakan sesuatu, seperti penguburan jenazah. Sambatan ini masih banyak dilakukan oleh masyarakat Jawa terutama yang tinggal di daerah pedesaan yang dilakukan secara turun-temurun sampai sekarang.

Budaya tolong menolong dan turut serta mengulurkan bantuan dalam Islam diterapkan di banyak hal. Tak terkecuali dalam unsur aspek kehidupan sosial, dimana kepedulian dalam perkara sosial mengharuskan kita untuk ikhlas dan lepas dalam membantunya. Membantu sahabat atau orang sekitar sama saja sebagai tindakan

\footnotetext{
${ }^{1}$ Suliatyo, konsep dan keperawantan nyeri, 2013
} 
menebar vibrasi syukur kepada Allah SWT. Energi ketulusan dalam bantuan itu akaan meneber kepada orang-orang yang dibantu. ${ }^{2}$

Sikap saling membantu, peduli, gotong royong menjadi ciri khas budaya dalam Islam, hal ini lantaran Allah secara langsung mengantarkan dalam dalil Al`quran kepada seluruh ummat manusia. Dalam Surat Al-Maidah ayat 2 Allah SWT berfirman:

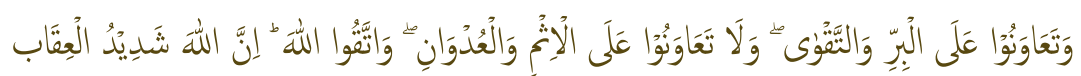

Dan tolong-menolonglah kamu dalam kebaikan dan ketakwaan. Dan janganlah tolong-menolong dalam berbuat dosa dan pelanggaran. Dan bertakwalah kamu kepada Allah, sesungguhnya siksa Allah saangat berat.

Eksistensi manusia di muka bumi ini tentu berbeda dengan mahluk Allah lainnya. Manusia adalah mahluk ahsanu taqwim (sebaik baik ciptaan Allah). Yang berakal. Secara sosial amaliyah, derajat manusia lebih tinggi dibandingkan dengan mahluk yang lain. Oleh karna itulah, Islam sebgai agama samawi tersempurna menyeru kepada pemeluknnya untuk menjaga kehormatannya dan juga menjaga kehormatan saudara seagama. Satu dengan yang lain saling bersaudara, itulah agama Islam. Cinta damai dan penuh dengan suasana saling membantu antar sesama. Salah satu ajaran nabi yang menganjurkan hal ini adalah,

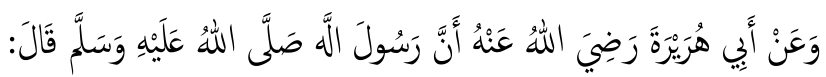

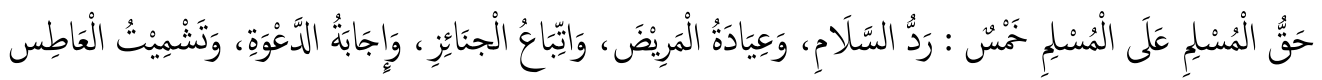

"Hak seorang muslim terhadap muslim yang lain ada lima, yaitu membalas salam menjenguk yang sakit, mengiringi (mengantar) janazah, memenuhi undangan, dan menjawab (mendoakan orang yang bersin)" 3

Begitulah Islam yang penuh dengan nuansa kepuedulian sosial. Tak cukup hanya disini, bahkan ummat Islam juga harus saling menjaga kehormatan saudara seagama ketika ada yang meninggal. Atas dasar inilah kemudian disyariatkan empat

\footnotetext{
${ }^{2}$ Hidayat, Ungkapan Hikmah

${ }^{3}$ Shohih Muslim 11:126.
} 
kewajiban yang diharus diperlalkukan kepada janazah. Yang pertama memandikan, kedua mengkafani, ketiga mensholati dan yang ke empat menguburkan. Keempat ritual ini bukan hanya memiliki nilai kepedulian sosial di dunia saja, melainkan juga sebagai tanda bahwa di antara ummat Islam pun harus ada kepedulian sosial akhirat. Apapun yang akan dihadapi si mayat di alam barzah nanti kita juga harus peduli. Coba kita potret dari ibadah sholat janazah, tentu nilai kepedulian terhadap kemaslaharan akhirat sangat tampak sekali. Semakin banyak yang sholaat maka semakin maslahah untuk simayit.

Persoalan yang muncul kemudian adalah bagaimana keempat aktivitas tersebut benar benar terlaksana sesuai dengan sunnah Nabi Muhammad SAW sehinga kemaslahatan yang diperoleh si mayat bukan hanya kemaslahatan semu, melainkan kemaslahatan yang konkret untuk bekal simayat ketika nantinya menempati alam berzah.

\section{METODOLOGI}

Adapun metodologi dari jurnal ini adalah menggunakan metode kepustakaan atau kajian pustaka (library research) yaitu sumber yang didapatkan oleh peneliti adalah bersumber dari buku-buku bacaan, karya ilmiyah, jurnal, penulis menganalisis, menyimpulkan serta memehami data-data yang ada sebagai bahan utama pembuatan jurnal sesuai dengan topic yang menulis bahas dalam jurnal ini.

\section{PEMBAHASAN}

"Beragam dan Unik" begitulah kiranya potret kebiasaan-kebiasaan penguburan jenazah yang telah berkembang di tengah dinamika kehidupan manusia saat ini. Keberagaman tersebut mesih tertata rapi sejak ratusan tahun yang lalu, hingga terwariskan dari generasi ke generasi. Oleh sebab itulah, walaupun sama agam (Islam) besar kemungkinan antara satu daerah degan daerah lain mempunyai tatacara tersendiri dalam melakukan prosesi penguburan.

Perbedaan catatatan berbeda-beda dalam penguburan jenazah akan ketara dari hal-hal unik dalam penguburan jenazah, misalnya membagi uang ketika di perjalanan 
pengantaran jenazah, meletakkan batu-batu kecil di atas keburan saat setelah proses penguburan telah usai, penyiraman kuburan dengan air, memberi gumpalan tanah di disekitar mayat, dan menutup liang lahat dengan kayu atau batu bata di sisi mayat sebelum di timbun. Trasisi tersebut sudah lumrah dan berakar di dalam masyarakat dan membudaya.

\section{Pengiringan Janazah}

Pengiringan janazah bukan hal yang tak berfadilah. Dalam arti, keutamaan pengantaran jenazah tidak kalah besar dari sholat jenazah. Sekalipun dalam proses perjalanan mengantarkan jenazah terlihat sepele, namun bila dilakukan dengan penuh keimanan dan keikhlasan maka janji nabi adalah qirod sebesar gunung Uhud di akhirat kelak. Nabi bersabda.

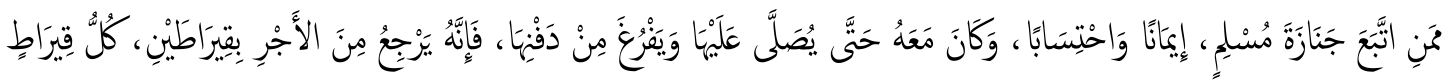

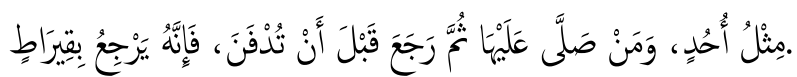

Artinya: "Barangsiapa yang mengiring janazah seoran muslim dengan sebuah keimanan dan mencari ridla Allah, orang itu mengiringi janazah sampai shalat selesai dan sampai usai menguburkannya, ia pulang membawa pahala dua qirath. Setiap qirath itu sama dengan gunung Uhud. Dan barangsiapa yang menshalatinya lalu pulang sebelum dimakamkan, dia pulang dengan membawa satu qirath. (HR Bukhari: 47)

Pada hadits tersebut sangat jelas sekali bahwa siapapun orangnya, tak peduli kaya miskin, pria wanita, pejabat atau rakyat, santri atau kiai, dan seterusnya akan diberi pahala 2 qiroth yang masing masing satu qiroth sama dengan ukuran gunung Uhud. Alasannya adalah masuk kategori lafadz "am" yang berkonsekuensi mencakup pada setiap orang Islam. Dari ini, sebenarnya kaum hawa juga mencakup dalam keumuman hadist tersebut. Namun, ketika dibenturkan dengan teks hadist lain, yaitu:

$$
\text { عن أم عطية رضي الله عنها قالت نهينا عن اتباع الجنائز ولم يعزم علينا }
$$

Artinya, "Dari Ummi Athiyyah RA, ia berkata, 'Kami dilarang untuk mengiringi jenazah dan larangan itu tidak dikuatkan atas kami, " (HR Bukhari dan Muslim). 
Maka dengan perkawinan dua hadist ini keumuman hadist yang pertama tertakhsis. Artinya seseorang wanita dilarang mengiringi jenazah di perjalanan. Namun pelarangan ini tidak sampai tingkatan haram, manyoritas ulama lebih memilih makruh dalam menafsirkan larangan pada hadist tersebut. Larangan ini bukan tampa alasan. Coba banyangkan wanita memikul peti. Tentu itu bukan pemandangan yang lumrah, meraka tidak diperkenankan karena berpotensi menimbulkan fitnah.

Dalam literatur kitab klasik terjadi satu kesepakatan mayoritas ulama (Syafi'iyah,Malikiyah, dan Hanabilah) bahwa paling utama pengiring jenazah berada di depan jenazah. Keutamaan ini bagi para pengiring yang berjalan kaki. Sedangkan bagi pengendara maka ulamak terbelah kedua pendapat. Jumhur ulamak selain Syafi'iyah sepakat bahwa sebenarnya tidak layak seorang pengantar berkendaraan. Lebih utama jalan kaki daripada berkendaraan. Akan tetapi bila terpaksa berkendaraan lantaran ada udzur semisal lemah karena tua/sakit maka lebih utama mereka mengiringi di belakang peti jenazah. Sedangkan imam Syafi'i tetap bersiteguh, bahwa para pengendara yang mengiringi jenazah disunnahkan di depan jenazah. ${ }^{4}$

Terlepas dari perdebatan ulamak mengenai pengiring yang berkendaraan, tampaknya ada satu hal yang dapat di petik. Yaitu bahwa sebenarnya mengiring jenazah memang lebih utama di depan. Kenapa demikian? Alasannya adalah lantaran ketika profesi pengantaran jenazah berlangsung, si pengiring berposisi sebagai syafi' I (pemberi pertolongan dalam mendapatkan rahmat Allah) bagi jenazah yang berposisi sebagai almasyfu'lah. Oleh sebab itulah, pengiring lebih utama didepan jenazah, bukan dibelakang. Demikian alasan yang di kemukakan Imam Nawawi. ${ }^{5}$

Dari paparan ulama di atas, satu hal yang harus diperhatikan bahwa siapapun orangnya yang sudah terbiasa mengantar jenazah dan kebetulan ia membiasakan diri berada dibelakang jenazah,maka tidak usah melarang orang lain berjalan didepan jenazah. Lantaran nyatanya lebih utama didepan jenazah daripada dibelakang jenazah.

Satu hal lagi adab yang perlu di perhatikan dalam mengantar jenazah,yaitu ketika para pengiring berdzikir. Dalam berdzikir,hendaknya para pengiring tidak usah

\footnotetext{
${ }^{4}$ al-Um, I:271; al-Falah, I:233; Raudhatul al-Thalibin, II:115

5 al-Majmu', V:278
} 
terlalu mengeraskan suaranya. Proses pengantaran jenazah harus berjalan dengan penuh kekhusyu'an dan ketenangan, tak boleh ada senda gurau. Kalau mengantar hanya untuk bercanda dan mengacaukan di perjalanan, maka lebih baik tidak usah ikut lantaran akan mengganggu pengiring yang khusyu' ${ }^{6}$

Mengantar jenazah tentu bukanlah tempat untuk ngobrol atau bicara yang tak ada gunanya. Bahkan,sudah seharusnya para pengantar dengan khidmat berkonsentrasi untuk memikirkan bekal apa yang sudah disiapkannya untuk perjalanan ke negeri akhirat. Karena salah satu hikmah dari mengantar jenazah adalah agar kita bisa mengingat kepentingan akhirat. Nabi bersabda,

$$
\text { ا مشؤا مع ا الجناءز تد كرك الا خره }
$$

"Iringilah jenazah maka kalian akan mengingat akhirat.",

\section{Menabur Uang}

Di sebagian daerah,lumrah tradisi membagi-bagikan uang receh ketika mengantar jenazah. Yang mengambil uang receh tersebut pada biasanya anak-anak kecil. Sehingga dipikiran anak-anak kacil timbul rasa riang gembira bila ada orang yang mati. Lantaran mereka akan dapat banyak uang. Tabur uang semacam ini memang belum di ketahui apa maksudnya. Yang jelas begitulah tradisi di sebagian daerah di Indonesia. Konon katanya, ini dilakukan dalam rangka bershodaqoh yang pahalanya diberikan kepada si mayyit.

Pada dasarnya, beredekah adalah anjuran agama. Bahkan bersedekah juga dianjurkan atas orang yang sudah meninggal. Terkait dengan ini, Rasulullah bersabda:

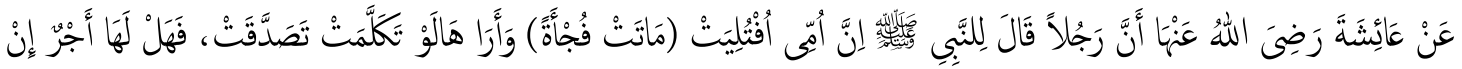

$$
\begin{aligned}
& \text { تَصَدَّقْتُ عَنْبا ؟ قَالَ : نَعَمْ. متفق عليه }
\end{aligned}
$$

"Dari Siti 'Aisyah Ra bahwa seorang laki-laki berkata kepada Nabi Muhammad SAW: "Ibu saya mati mendadak, dan saya yakin seandainya dia bisa bicara, dia

\footnotetext{
${ }^{6}$ Maraqiyal-Falah,233

${ }^{7}$ Musnadu Ahmad,XXII:296
} 
bersedekah, apakah ibu saya mendapat pahala, seandainya saya bersedekah untuk ibu saya? Rasulullah menjawab, "ya ada pahala bagi ibumu.",

Berdasarkan hadist ini, sangatlah jelas bahwa pahala sedekah sampai kepada mayyit. Akan tetapi dalam bersedekah hendaknya dengan cara yang baik. Bisa dengan memberikan sumbangan kepada masjid, fakir miskin, atau memberikan jamuan kepada tamu-tamu yang berta'ziyah.

Tabur uang, sekalipun dimaksudkan untuk bersedekah maka lebih baik dihindari. Alasannya, hal tersebut tidak sesuai dengan tuntunan Nabi. Nabi hanya memperbolehkan sedekah atas nama mayyit, bukan berarti caranya seperti tabur uang ketika mengantar jenazah. Cara ini hanya akan menimbulkan kesan Israf (menghamburkan uang). Kesan lain yang juga timbul adalah kibr (kesombongan). Coba perhatikan,kalau ada orang menabur uang di perjalanan, jelas itu menunjukkan efek kesombongan. Nah, kalau dua kesan ini benar-benar muncul di tengah-tengah masyarakat maka tradisi tabur uang ini bukan hanya harus dihindari,melainkan wajib dihindari.

\section{Penutup Jenazah Di Liang Lahat}

Ada dua model liang kubur yang sering digunakan dalam penguburan jenazah. Pertama liang campuri, yakni liang kubur yang bagian tengahnya digali sekiranya cukup untuk menaruh mayit, modal ini untuk tanah yang gembur. Kedua, liang lahat: yakni liang kubur yang sisi sebelah baratnya digali sekiranya cukup untuk menaruh mayit. Model ini untuk tanah yang keras dan lebih baik dari liang cempuri.

Dari model ini biasanya masyarakat kita menaruh kayu atau bata dilakukan agar mayat tidak tersentuh langsung oleh tanah. Karena kalau mayat bersentuhan langsung dengan tanah, maka hukumnya adalah haram. ${ }^{9}$ Caranya adalah mayat dimasukkan ke liang lahat dalam kondisi dimiringkan ke kanan sehingga lambungnya yang kanan berada dibawah. Wajah menghadap kiblat serta pipinya menempel ke tanah, setelah itu

\footnotetext{
${ }^{8}$ Shahih al-Bukhariy, V:187

${ }^{9}$ Lianatuttholibin, II/134. Syarah Mukthashor Holil, V/441.
} 
kepalanya diberi batu, bata atau sesuatu yang lebih tinggi agar mayat tidak berpaling dari arah kiblat. Kemudian di atas mayat diberi penutup liang. ${ }^{10}$

\section{Penguburan Dengan Peti}

Penguburan bersama dengan peti memang masih belum lumrah di masyarakat Islam Indonesia. Akan tetapi, di kalangan prajurit Negara atau para tentara hal ini sudah lumrah. Tak peduli apakah agama para tentara tersebut Islam atau yang lainnya.

Terkait dengan penguburan mayat dengan peti, ulama' berbeda pendapat. Hanafiyan dan Syafi'iyah menghukumi makruh meskipun ada wasiat dari mayat, kecuali ada udzur atau kebutuhan. Misalnya, tanahnya berair, adanya binatang buas yang dikhawatirkan akan memakan mayyit bila tidak di tempatkan dalam peti. Menurut Syafi'iyah, penguburan dengan peti bisa menghilangkan kerendahan dan ketundukan diri seorang hamba pada Allah. Sementara dari kalangan Hanabilah menjustifikasi kemakruhannya secara mutlaq (baik ada kebutuhan atau tidak). Sedangkan Malikiyah menghukuminya dengan khilaful awla (menyalahi yang utama). ${ }^{11}$

Demikianlah argument para ulama mengenai penguburan dengan peti. Tidak ada satupun ulama yang berargumen itu sunnah. Bahkan, hanya menimbulkan kesan menghamburkan harta maka bisa berkonsekuensi haram. Oleh sebab itulah, tradisi di kemiliteran tidak usah di tiru di masyarakat. Bahkan, kalau perlu sudah seharusnya, pemerintah negeri ini mengubah kebiasaan tersebut, terutama ketika tentara yang meninggal beragama Islam. Ingat! Malaikat Mungkar -Nakir tak akan menanyakan persoalan apakah si mayyit bawa peti atau tidak ke liang lahat. Semua hamba Allah di perlakukan sama di hadapan hukum Allah. Bila memang banyak dosa sekalipun dikubur dengan peti maka tetap di siksa. Dan siapapun orangnya, jika amal kebaikannya lebih banyak maka ia akan mendapat tempat yang damai dan indah di alam barzah. Mudahmudahan kita bisa seperti ini.

\footnotetext{
${ }^{10}$ al-Mughni,II/374

${ }^{11}$ Hasyi'ah al-Bujairimy,V:29; Fathul Wahab, I:174;al-Fiqh 'ala Madzaibul Arba'ah,I:837
} 


\section{Bentuk Kuburan}

Di Indonesia bentuk kuburan sangat beragam. Kalangan level bawah biasanya hanya memasang batu nisan di bagian kepala kuburan. Sedangkan masyarakat level menengah ke atas gemar sekali membangun kuburan hingga kuburan dapat terlihat indah. Bahakan,sampai ada yang di keramik. Lantas, manakah yang sesuai dengan tuntunan Nabi?

Di suatu kesempatan,seorang sahabat Nabi, Jabir pernah menyampaikan pesan dari Nabi tentang masalah bentuk kuburan yang ideal.

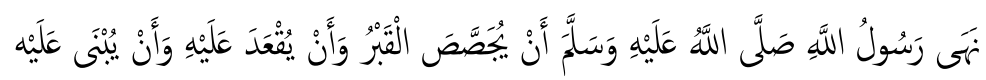

"Dari Jabir,ia berkata: Rasulullah SAW melarang pengapuran kuburan, duduk di atas kuburan, dan membangun kuburan.” [Shahih Muslim,970]

Dari hadist ini, sebagian ulama Syafi'iyah berkesimpulan bahwa kuburan yang di perlakukan tiga hal sebagaimana tersebut di atas adalah haram. Yaitu mengurapi dengan kapur, duduk di atas kuburan, dan membangun kuburan. Pembangun kuburan dengan memberinya semen atau keramik terkadang mengantarkan manusia pada berlebih-lebihan. Oleh sebab itulah hal ini di haramkan. Lantas bagaimana dengan makam Nabi?

Pada dasarnya makan Nabi tidak pernah sengaja dibangun sebuah bangunan. Dan kalaupun saat ini Beliau di semayamkan dikuburan yang dibangun, maka bangunan itu sebenarnya sudah ada sebelum Beliau wafat, lantaran bangunan tersebut merupakan rumah Beliau. Beliau memang di makamkan di rumahnya. Keistimewaan ini adalah khususiyyah Nabi yang tak berlaku bagi umatnya. Jadi, bagi umatnya tetap tidak boleh membangun apapun di atas pemakaman sudaranya yang meninggal. ${ }^{12}$

Namun, jumhur ulama (mayoritas) ulama tidak lantas mengharamkan ketiga hal diatas. Dalam hal mengapur dan membangun kuburan, hukumnya hanya makruh, sedangkan duduk di atas kuburan mutlak diharamkan. Hal ini dikarenakan pembangunan dan pengapuran terkadang memang ada tujuan tetentu untuk dilakukan, misalnya agar mudah untuk diziarahi. Yang diharamkan dalam hal pembangunan

${ }^{12}$ Syarh al-Mukhtasar 'ala Bulugh al-Maram, IV:60 
makam adalah ketika pembangunan tersebut menyebabkan sanak family atau orang lain terlalu mengagungkan si mayyit hingga mirip dengan orang-orang Nasrani dan Yahudi yang menjadikan kuburan para Nabi mereka sebagai tempat bersujud. Pembangunan kuburan model inilah sebenarnya yang sampai mengantarkan pada keharaman. ${ }^{13}$ Terlepas dari perdebatan antara makruh dan haram, ada satu hal yang pasti bahwa idealnya sebuah makam memang seharusnya dibiarkan natural tanpa bangunan. Bentuknya yang ideal ditinggikan dengan ukuran satu jengkal atau empat jari. Demikianlah criteria yang diungkapkan para ulama. ${ }^{14}$

\section{Membersihkan Kuburan}

Sungguh hebat kepedulian saudara seiman dalam Islam. Umat Islam di Indonesia tak jarang membersihkan kuburan familinya di pemakaman. Namun, bila ada hajat maka kemakruhan tersebut hilang dan di perbolehkan. Hajat tersebut misalnya rerumputan terlalu banyak hingga menutupi kuburan. Dalam kondisi seperti ini maka boleh-boleh saja membersihkan sekitar kuburan. ${ }^{15}$ Pendapat ke tiga disampaikan oleh Hanabilah. Menurut mereka, boleh-boleh saja membersihkan kuburan. Malah mereka mengkritik alasan yang disampaikan oleh Syafi'iyah dan Hanafiyah. Alasan rerumputan itu memohonkan ampun pada Allah adalah kurang tepat. Karena adzab kubur dan pelepah kurma yang masih hijau tidak ada kaitannya dalam meringankan adzab kubur. Apa yang dilakukan oleh Nabi adalah Khushusiyyah bagi Beliau lantaran Nabi ada sang pemberi Syafa'at. 16

\section{KESIMPULAN}

Dari ketiga ragam diatas, dapat disimpulakan bahwa apa yang dilakukan Rasul belum tentu khususiyyah beliau, jadi besar kemungkinan bahwa sesuatu yang masih hijau atau masih hidup bisa mendoakan ampunan bagi si mayyit. Hal ini sesuai dengan tuntutan Rasul. Namun, satu catatan yang harus diperhatikan. Bahwa jangan sekali-kali

\footnotetext{
${ }^{13}$ Subulu al-Salam,II:111

${ }^{14}$ Tabyinu al-Haqa'iq,III:211;al-Majmu”,V:295,Fathu al-Mu'in, II:135; Syarah al-Kabir li ibni Qodamah, II:383

${ }^{15}$ Fiqhul Islamy Wa Adillatuhu,II:672; Hasyi'ah al-Thahawi, I:415

${ }^{16}$ Syarah al-Mumta',III:180
} 
kita menyengaja untuk menanam pohon di atas kuburan mayyit lantaran menduga mayyit di siksa didalam kubur. Kemudian kita bermaksud menanami tumbuhan demi membantu meringankan siksa. Hal ini jelas tidak boleh lantaran kita sudah berprasangka buruk terhadap si mayyit bahwa ia di siksa, padahal kita masih belum tahu betul apa yang terjadi di alamnya.

\section{Daftar Pustaka}

Suliatyo, konsep dan keperawantan nyeri, 2013

Shohih Muslim 11:126.

Hasyi'ah al-Bujairimy,V:29; Fathul Wahab, I:174;al-Fiqh 'ala Madzaibul Arba'ah,I:837

Shahih al-Bukhariy, V:187

Lianatuttholibin, II/134. Syarah Mukthashor Holil, V/441.al-Mughni,II/374

Syarh al-Mukhtasar 'ala Bulugh al-Maram, IV:60 Subulu al-Salam,II:111

Tabyinu al-Haqa'iq,III:211;al-Majmu”,V:295,Fathu al-Mu'in, II:135; Syarah al-Kabir li ibni Qodamah, II:383

Fiqhul Islamy Wa Adillatuhu,II:672; Hasyi'ah al-Thahawi, I:415 Syarah alMumta',III:180 